Accepted refereed manuscript of: Comerford DA (2020) Review of A Fast and Frugal Finance: Bridging Contemporary Behavioral Finance and Ecological Rationality by William P. Forbes, Aloysiys Obinna Igboekwu, \& Shabnam Mousavi. Journal of Economic Psychology, 80, Art. No.: 102278. https://doi.org/10.1016/j.joep.2020.102278

(C) 2020, Elsevier. Licensed under the Creative Commons Attribution-NonCommercial-NoDerivatives 4.0 International

http://creativecommons.org/licenses/by-nc-nd/4.0/

\title{
Review of A Fast and Frugal Finance: Bridging Contemporary Behavioral Finance and Ecological Rationality by William P. Forbes, Aloysius Obinna Igboekwu, \& Shabnam Mousavi.
}

\author{
David A. Comerford ${ }^{1}$
}

I write this review under lockdown amid a global pandemic. So far today (March $25^{\text {th }} 2020$ ), the Dow Jones is up 5 percent. Last week trading was suspended following a 13 percent fall. Financial markets across the globe are struggling to price the risk posed by an unprecedented phenomenon. Given this uncertainty, the equity premium puzzle might not look like such a puzzle after all.

I was surprised that the equity premium puzzle did not come in for discussion in William Forbes, Aloysius Obinna Igboekwu and Shabnam Mousavi's new book as it seems to offer a neat case study with which to illustrate some of the work's key points. Among these is that a "constructivist form of rationality is prevailing in standard finance" to the exclusion of a distinct conceptualization of rationality, "ecological rationality" (Forbes et al., 2019, p. 10).

I will define what is meant by ecological rationality when I come to discuss Chapter 2 of Forbes et al. below, but first let me clarify that a "constructivist form of rationality" assesses the quality of a decision by its internal, logical coherence. The pervasiveness of this view of rationality is reflected in this recent quote from Colin Camerer (2020) in which he discusses the context in which he conducted his PhD: "Chicago finance — at that time - was extremely (sic) hostile to any models or even intuitions about limits on rationality". Note that Camerer could have said "limits on cognitive resources" but instead he refers to deviations from expected utility theory as manifesting "limits on rationality".

Another way of making this point is to say that the top journals in finance are written in the language of expected utility theory. Their readers, authors, and reviewers have learnt to communicate with one another through that language and, as Richard Thaler points out (2015), some could not conceive of a world beyond its terms. For those motivated to shake the finance world out of its delusion that markets are always and everywhere efficient, the only recourse was to demonstrate systematic violations of expected utility theory. Hence, behavioural finance has tended to focus on internal inconsistencies in judgment processes. These violations were initially dismissed as inconsequential by some (e.g. Miller, 1986; Charness, Karni, \& Levin, 2010), but with time the gatekeepers have given some terms that have allowed them form part of the discourse: beta-delta, $\mathrm{x}$-capm, the loss-aversion parameter etc. The current consensus is that expected utility theory is a normative benchmark that requires modification to take account of the behavioural biases induced by heuristics (e.g. Thaler, 2015; Statman, 2019; Gennaioli, \& Shleifer, 2020).

In his foreword to Forbes et al. (2019), Gerd Gigerenzer takes issue with the dismissal of heuristic-induced noise as bias. He points out that Wikipedia is replete with entries on various cognitive biases and proposes that a more useful scientific enterprise would be to bring heuristics from the margins of finance to its centre. An elaboration of this case forms the basis of chapter 1 .

\footnotetext{
${ }^{1}$ David A. Comerford, Behavioral Science Centre, Economics Division, University of Stirling, FK9 4LA, UK, phone: +44 1786-467317, email: david.comerford@stir.ac.uk.
} 
A key argument in favour of the fast-and-frugal approach set out in chapter 1 is that "less is more". In small samples a multivariate regression model will tend to overfit the data and outof-sample predictions will tend to suffer. In these conditions, reliance on a single cue (e.g. name recognition) can outperform more sophisticated models.

Chapter 2 picks up the baton by arguing that heuristics manifestly guide behaviour. A favourite example here is the gaze heuristic (McBeath, Shaffer \& Kaiser, 1995; summarized in Forbes et al., 2019, p. 24): a child catches a ball not by calculating velocity, trajectory, gravity etc. but by implicitly recognizing that a ball will land where she is if she can follow the ball's motion without adjusting her gaze. The example is compelling; it makes sense when applied to the behaviour of the hypothetical child and has the added allure that, once pointed out, it speaks to our own experience of catching balls. It also speaks to something larger - we know that the gaze heuristic is not amongst the laws of physics and yet the gaze heuristic works just as well as the arduous normative procedure. Add in time pressure (the ball is at fifteen foot and falling rapidly) and the fast-and-frugal rule of thumb works better. Ecological rationality!

Later chapters of the book make the case that fast-and-frugal heuristics can be usefully applied to various judgments and decisions in the world of finance: Chapter 4 shows a less-ismore approach to predicting financial regulation. Chapter 6 applies fast and frugal heuristics to asset pricing, Chapter 7 to portfolio selection, Chapter 8 to financial analysis and Chapter 9 to predict investors' responses to earnings streaks.

So, back to the Equity Premium Puzzle. In his foreword to this book, Gerd Gigerenzer offers an argument that should give us pause in judging what is irrational in financial markets. Standard finance models conflate uncertainty and risk (for it would be impossible for these models to price assets otherwise). If our idea of risk is inferred from too small a sample of market returns, perhaps we have overfitted the data? Perhaps the equity premium reflects a crowd wisdom bourn of ecological rationality?

The problem with using "ecological rationality" as a benchmark is one of degrees of freedom: which external criterion ought we judge against? Gigerenzer's foreword implies the most ambitious: correspondence with truth. He points out that expected utility theory gives rise to an "illusion of certainty"; some wrongly extrapolate that they possess insight on the underlying data generation process that governs financial markets.

The authors generally content themselves with more modest benchmarks for judging rationality: is a heuristic profitable? If it is not profitable (e.g. overconfidence), does it at least reassure clients? If it is neither profitable nor reassuring (e.g. the recognition heuristic), does it at least describe how people actually behave?

A difficulty faced by the reader is that the criterion against which fast-and-frugal heuristics are assessed sometimes changes from one paragraph to the next. This problem is heightened by the tone of the book. It often reads as polemic. At one point, Gigerenzer's Fast-and-Frugal research program is likened to "Fight Club" (p. 97). More worryingly, some papers are recruited in support of the Fast-and-Frugal cause that, with more even-handed exposition, might be viewed as demonstrating its weaknesses. For instance, Alter and Oppenheimer (2008) show that stocks that have fluent ticker codes (e.g. KAL, as opposed to the disfluent XWF) enjoy a premium initially. The book does not mention that the ticker codes are assigned arbitrarily and so, unlike a brand name, could not possibly contain useful 
information regarding the firm's prospects. In the context of the book's wider claims for ecological rationality, a fast-and-frugal reader might be misled by such elisions.

That said, the book offers many valuable insights and interesting case studies. I found the examples on applying fast-and-frugal heuristics to regulation particularly enlightening. It is just a pity that the authors did not devote their considerable knowledge to delivering a handbook on how and when to use fast-and-frugal heuristics, e.g. the important distinction between working with small datasets versus the very large ones that lend themselves to machine learning. In sum, this book opens an important debate and makes some strong suggestions for broadening the scope of enquiry in finance.

\section{References:}

Alter, A. L., \& Oppenheimer, D. M. (2006). Predicting short-term stock fluctuations by using processing fluency. Proceedings of the National Academy of Sciences, 103(24), 9369-9372.

Camerer, C. (2020) Interview with Money On The Mind. Accessed at:

https://www.moneyonthemind.org/post/interview-with-colin-camerer

Charness, G., Karni, E., \& Levin, D. (2010). On the conjunction fallacy in probability judgment: New experimental evidence regarding Linda. Games and Economic Behavior, 68(2), 551-556.

Forbes, W. P., Igboekwu, A. O., \& Mousavi, S. (2019). A Fast-and-frugal Finance: Bridging Contemporary Behavioral Finance and Ecological Rationality. Academic Press.

Gennaioli, N., \& Shleifer, A. (2020). A Crisis of Beliefs. Princeton University Press.

McBeath, M. K., Shaffer, D. M., \& Kaiser, M. K. (1995). How baseball outfielders determine where to run to catch fly balls. Science, 268(5210), 569-573.

Miller, M. H. (1986). Behavioral rationality in finance: The case of dividends. Journal of Business, S451-S468.

Statman, M. (2019). A Second Generation Behavioral Finance. Behavioral Finance: The Coming Of Age, 1.

Thaler, R. H. (2015). Misbehaving: how economics became behavioural. Allen Lane. 